\title{
Sense of coherence as a protective factor in chronic urticaria
}

\author{
Alicja Ograczyk , Joanna Miniszewska², Anna Pietrzak¹, Anna Zalewska-Janowska ${ }^{1}$ \\ ${ }^{1}$ Psychodermatology Department, Medical University of Lodz, Lodz, Poland \\ ${ }^{2}$ Department of Health Psychology, Institute of Psychology, University of Lodz, Lodz, Poland
}

Adv Dermatol Allergol 2017; XXXIV (2): 168-173

DOI: https://doi.org/10.5114/ada.2017.67084

\begin{abstract}
Introduction: Chronic urticaria (CU) seems to be perceived as a psychodermatological disorder. Different psychological factors play an important role in CU triggering and course. One of them is a sense of coherence (SOC), which is believed to be a protective factor against anxiety and depression.

Aim: To investigate quality of life $(\mathrm{Q} o \mathrm{~L})$ in CU patients and to compare selected psychological parameters (anxiety, depression and sense of coherence) between CU individuals and the control group.

Material and methods: The study comprised 46 female patients with chronic urticaria and 33 healthy females as a control group. The following methods were employed: Urticaria Activity Score (UAS), Hospital Anxiety and Depression Scale (HADS), Sense of Coherence Questionnaire (SOC-29) and Dermatology Life Quality Index (DLQI). Results: The CU patients presented a significantly higher anxiety level in comparison to the control group $(z=4.488$; $p<0.001)$. There were no statistically significant differences regarding depression intensity and SOC. In both groups anxiety and depression negatively correlated with global SOC and all its components. Disease severity positively correlated with QoL $(\rho=0.46, p<0.01)$ and negatively with global SOC $(\rho=-0.33, p<0.05)$.

Conclusions: Bearing in mind higher prevalence of anxiety and depressive symptoms in our CU group, it would be useful to perform screening of these aspects in all CU patients and subsequently develop respective psychological interventions, based on enhancement of personal resources.
\end{abstract}

Key words: chronic urticaria, depression, anxiety, sense of coherence.

\section{Introduction}

Chronic urticaria (CU) affects approximately 1-4\% of general population. Disease lasts more than 6 weeks and is characterized by recurrent wheals accompanied by pruritus [1, 2]. The CU is perceived as a psychodermatological condition, so psychological factors can influence hives development and exacerbation [3-6]. Additionally, the disease itself and its consequences can affect psychological well-being and worsen quality of life [7-9]. As a result patients can manifest mood disorders, anxiety and/or depression [10-13]. The prevalence of anxiety is evaluated even up to $30 \%$ [11], whereas depression accompanies approximately $17-40 \%$ of CU patients $[4,11,13]$.

Although it is perceived as a difficult condition to cope with, chronic urticaria does not have to significantly impair quality of life (QoL). On the basis of Lazarus stress conception, illness is an interaction between disease de- mands (i.e. CU severity, clinical presentation, relapsing course, itch) and personal resources (PR) [14]. Personal resources are of a key relevance in coping with stress in daily life. They are defined as relatively stable individual features (biological, psychological, interpersonal), environmental attributes (support groups, surrounding characteristics) and their mutual interactions. They play an important intermediary role between stressors and coping strategies applied. As a result, a human being can fulfill his needs and achieve his aims effectively [14-16]. A sense of coherence is believed to be one of the PRs [14].

Sense of coherence (SOC) is defined as a generalized way of world perception (taking into account cognitive and emotional aspects), which allows to notice incoming stimuli (internal and external) as understandable, under control and meaningful $[14,17]$. Sense of coherence comprises 3 components: comprehensibility (incoming stimuli are perceived as coherent and structured; as a result

Address for correspondence: Alicja Ograczyk, Psychodermatology Department, Medical University of Lodz, 251 Pomorska St, 92-213 Lodz, Poland, phone: +48 4227257 89, e-mail: alicja-ograczyk@umed.lodz.pl

Received: 6.08.2015, accepted: 3.04.2016. 
a person can understand, explain and predict phenomena), manageability (the element responsible for assessment of resources; abilities to cope with demands related to incoming stimuli; due to them an individual does not feel helpless when facing difficulties) and meaningfulness (the belief that it is worth engaging in life challenges and investing energy in them; a human being is convinced that his actions have sense) [14, 17-19].

Individuals with strong SOC assess less life events as dangerous, apply active coping strategies and they are more motivated to overcome difficulties. They are more prone to seek, achieve and use available resources, so they are more successful in their efforts than the ones with lower SOC. It was observed that SOC plays a protective role against depression and anxiety $[14,17,18]$.

\section{Aim}

The aim of our study was to investigate QoL in CU patients and to compare selected psychological parameters (stress, anxiety, depression and sense of coherence) between CU individuals and the control group. The second goal was to investigate the relationships between the above variables in both studied groups.

\section{Material and methods}

The research group initially comprised 51 adults suffering from chronic urticaria (with no other dermatological conditions). Due to significant gender disproportions (only 5 males were recruited), finally, only female results
(46 patients) were statistically analyzed. All the patients presented chronic inducible urticaria: dermatographic urticaria - 25 respondents (positive test with moderate stroking of the skin by wooden spatula), delayed pressure urticaria - 11 ones (positive test with suspension of weights over the shoulder for $15 \mathrm{~min}$ ) and cold contact urticaria - 10 patients (positive test with the use of a melting ice cube held in a thin plastic bag for $5 \mathrm{~min}$ ). Fifteen individuals indicated an important role of stress in disease exacerbation.

The study included also a control group of 33 healthy females consulting dermatologists due to common warts and melanocytic nevi (individuals with any other dermatological conditions or systemic, metabolic and psychiatric disorders were excluded from the study). The participants were recruited at the Allergology Clinic of the Allergy and Asthma Diagnostic and Treatment Centre, Dermatology Clinic in the Psychodermatology Centre and Dermatology, Pediatrics Dermatology and Oncological Dermatology Clinic in Lodz. The detailed demographic characteristics of the respondents are presented in Table 1.

The median disease duration ( \pm SEM) was $11 \pm 10.4$ months with a range of 1.5 months to 25 years.

The study was approved by the Medical University of Lodz Bioethics Committee and conducted in accordance with the Helsinki Declaration. Patients gave their informed consent to participate in the research.

The following methods were applied in the study:

1. Authors' questionnaire consisting of questions about demographic and clinical data, i.e. disease duration

Table 1. Sociodemographic characteristics of the study group

\begin{tabular}{|c|c|c|c|c|c|c|}
\hline \multirow[t]{2}{*}{ Parameter } & \multicolumn{3}{|c|}{ CU patients } & \multicolumn{3}{|c|}{ Control group } \\
\hline & $M$ & SD & Range & $M$ & SD & Range \\
\hline \multirow[t]{2}{*}{ Age } & 44.6 & 14.2 & $21-68$ & 46.3 & 14.7 & $18-78$ \\
\hline & $N$ & & Fraction & $N$ & & Fraction \\
\hline \multicolumn{7}{|l|}{ Educational level: } \\
\hline Primary & 6 & & 0.13 & 1 & & 0.03 \\
\hline Occupational & 5 & & 0.11 & 8 & & 0.24 \\
\hline Secondary & 18 & & 0.40 & 13 & & 0.40 \\
\hline University & 17 & & 0.36 & 11 & & 0.33 \\
\hline \multicolumn{7}{|l|}{ Marital status: } \\
\hline Single & 10 & & 0.22 & 5 & & 0.15 \\
\hline Married & 25 & & 0.54 & 21 & & 0.64 \\
\hline Widow & 3 & & 0.07 & 3 & & 0.09 \\
\hline Divorced & 8 & & 0.17 & 4 & & 0.12 \\
\hline \multicolumn{7}{|l|}{ Residence place: } \\
\hline City & 37 & & 0.80 & 31 & & 0.94 \\
\hline Country & 9 & & 0.20 & 2 & & 0.06 \\
\hline
\end{tabular}


and severity, frequency of urticaria recurrences and exacerbation reasons.

2. Urticaria Activity Score 7 (UAS 7) - the scale to estimate urticaria severity. The tool is recommended by the EAACI/GA2LEN/EDF guidelines. UAS was assessed as the sum of two scores (range: $0-6)$ - number of hives (0-3) and pruritus intensity (0-3). The disease severity was estimated over a period of 7 days, resulting in a weekly score (UAS 7) - range from 1 to 42 [20, 21].

3. Visual analogue scale (VAS) - the tool was used to measure itch intensity. It is a $10 \mathrm{~cm}$ continuum with 0 indicating no itch and 10 as the most imaginable intensity of itch (range from 0 to 10). Scores from 0 to 3 are treated as mild, 3-6 as moderate, 7-9 as severe and 10 as very severe [22].

4. Hospital Anxiety and Depression Scale HADS (Zigmond, Snaith, 1983) - the scale used as a screening tool for anxiety (7 items) and depression (7 items). Each statement is evaluated on a four-point scale (assessed from 0 to 3) and the results are summed up separately for two subscales; the higher the score, the more anxiety/depression symptoms the patients present. The scores from 0 to 7 are interpreted as a normal anxiety/depression level, from 8 to 10 as mild, from 11 to 15 as moderate and from 16 to 21 as severe. The result above 11 can indicate mood disorders (at present or in the past) $[23,24]$.

5. Sense of Coherence Questionnaire SOC (Antonovsky 1983, Polish adaptation by the Occupational Medicine Department, The Institute of Occupational Medicine in Lodz 1993) - the method to estimate a sense of coherence and its three components - comprehensibility, manageability, and meaningfulness. The scale consists of 29 statements, each item is evaluated on a seven-point scale. The tool allows to obtain the global result and separate scores for each of three subscales. The higher the scores, the stronger sense of coherence is observed. It is thought that healthy functioning individuals obtain about $120-130$ points $[17,25,26]$.

6. Dermatology Life Quality Index DLQI (Finlay, Khan 1994; Polish adaptation Szepietowski et al., 2004) the scale to evaluate the dermatological patients' QoL. It comprises 10 statements, the responses are given on a four-point scale. The higher the score, the worse QoL is. The total result equals 0 or 1 , is interpreted as normal QoL. The scores of 2 and above indicate QoL impairment: namely points from 2 to 5 - slight, from 6 to 10 - moderate, between 11 to 20 - severe and from 21 to 30 - very severe [27-29].

\section{Statistical analysis}

The Statistica package (version 12) was used for statistical analysis. Mean (M), standard deviation (SD), median values (Me), standard error of measurement (SEM), percentiles (25-75\%), minimum (min) and maximum (max) values are presented. Some of analyzed variables did not meet a normal distribution criterion, so nonparametric tests such as Mann-Whitney U-test ( $\mathrm{z}$ ) and Spearman's rank correlation test $(\rho)$ were employed. The statistical significance level was set at $p<0.05$.

\section{Results}

\section{Disease characteristics and psychological measures}

The median UAS 7 score was 35 (range: 7-42; SEM = 1.40). The median VAS itch result was 3 (range: 0.1-10; SEM $=2.17$ ), which can be interpreted as pruritus of moderate intensity. Disease severity positively correlated with itch intensity $(\rho=0.34, p<0.05)$ and QoL $(\rho=0.46$, $p<0.01)$ and negatively with a global sense of coherence $(\rho=-0.33, p<0.05)$. Itch intensity was positively associated with QoL $(\rho=0.51, p<0.001)$. The relationships between age, disease duration and psychological parameters were not observed $(p>0.05)$.

\section{Quality of life in CU patients}

Analyzing the results regarding QoL, 12 urticaria patients evaluated it as normal, and 34 noticed disease influence on their functioning. Fifteen respondents assessed impairment as slight, 10 as moderate, 8 as severe and 1 as very severe.

The statistically significant correlations between QoL and anxiety, depression were not noted $(p>0.05)$.

\section{Anxiety, depression and sense of coherence in studied groups}

First of all, CU patients presented a significantly higher anxiety level $(z=4.488$; $p<0.001)$ in comparison to the control group (Figure 1). However, we did not observe any statistically significant differences between groups regarding depressive symptoms $(p>0.05)$. Detailed evaluation of anxiety and depression intensity is presented in Table 2.

Secondly, comparing a sense of coherence and its components, no statistically significant results were found between the studied groups $(p>0.05)$. But, it is worth underlying that CU patients obtained high results regarding global SOC and mean scores in three subscales (total: $141.6 \pm 27.6$ (mean \pm SD); comprehensibility: 48.1 \pm 12.4 , manageability: $50.1 \pm 10.9$ and meaningfulness: $43.4 \pm 7.7)$.

Finally, a sense of coherence and its components negatively correlated with anxiety and depression intensity in both groups. In CU patients correlation coefficients were higher. Of note, relations between manageability and anxiety, and total SOC and anxiety presented the strongest associations in our study (Table 3), underlying an opposite SOC role to symptoms of mood disorders. 
Table 2. The assessment of anxiety and depression intensity in the chronic urticaria (CU) patients group and in the control group

\begin{tabular}{lcccc}
\hline Variable & \multicolumn{2}{c}{ CU patients } & \multicolumn{2}{c}{ Control group } \\
\cline { 2 - 5 } & $\boldsymbol{N}$ & Fraction & $\boldsymbol{N}$ & Fraction \\
\hline Anxiety intensity: & 25 & & 27 & 0.82 \\
\hline Normal & 9 & 0.54 & 5 & 0.15 \\
\hline Mild & 7 & 0.20 & 0 & 0.00 \\
\hline Moderate & 5 & 0.15 & 1 & 0.03 \\
\hline Severe & & 0.11 & & 0.85 \\
\hline Depression intensity: & 36 & & 28 & 0.12 \\
\hline Normal & 10 & 0.78 & 4 & 0.03 \\
\hline Mild & 4 & 0.22 & 1 & 0.00 \\
\hline Moderate & 1 & 0.08 & 0 & \\
\hline Severe & & 0.02 & & \\
\hline
\end{tabular}

$N$ - number of people in a group.

\section{Discussion}

We showed a substantial impairment of QoL in 34 patients. Eight of them estimated it as severe and 1 as very severe. The worse QoL in the CU group was observed by many researchers [30-34]. We noted that disease severity and pruritus intensity positively correlated with QoL. Thus, it could be directly associated with CU specific as chronic course, the lesions on exposed parts of the body, together with difficulties in controlling symptoms [11, 13, 35]. Other studies also revealed similar relations between CU severity, itch and QoL [7, 32-35].

Moreover, we also observed statistically significant differences between CU patients and the control group. They concerned an anxiety level, which was higher in individuals suffering from urticaria. This result is con-

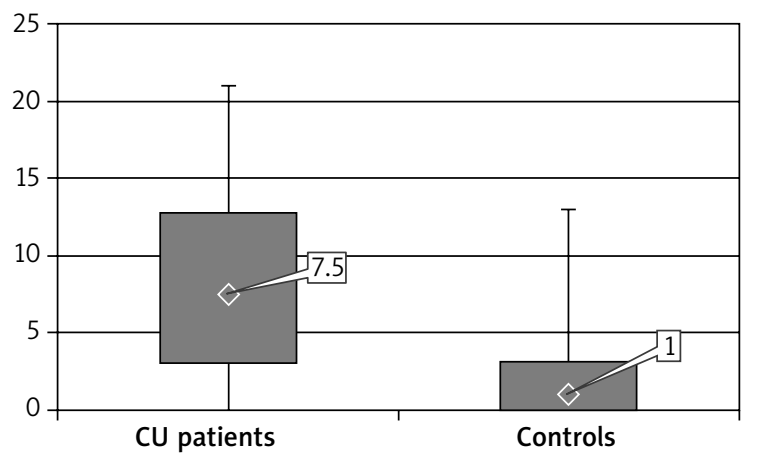

Figure 1. Comparison of anxiety intensity in CU patients and control group

Me, $25 \%-75 \%$ percentiles (box), min and max values are presented.

Table 3. Correlations between sense of coherence and anxiety and depression in the chronic urticaria (CU) patients group and in the control group

\begin{tabular}{|c|c|c|c|c|c|}
\hline \multirow{2}{*}{\multicolumn{2}{|c|}{ Correlations between }} & \multicolumn{2}{|c|}{ CU patients } & \multicolumn{2}{|c|}{ Controls } \\
\hline & & $\rho$ & $p$ & $\rho$ & $p$ \\
\hline Comprehensibility & \multirow{4}{*}{ and anxiety } & -0.49 & $<0.001$ & -0.36 & $<0.01$ \\
\hline Manageability & & -0.65 & $<0.001$ & -0.51 & $<0.001$ \\
\hline Meaningfulness & & -0.45 & $<0.001$ & -0.44 & $<0.001$ \\
\hline Sense of coherence (total) & & -0.62 & $<0.001$ & -0.48 & $<0.001$ \\
\hline Comprehensibility & \multirow{4}{*}{ and depression } & -0.39 & $<0.01$ & -0.36 & $<0.01$ \\
\hline Manageability & & -0.61 & $<0.001$ & -0.53 & $<0.001$ \\
\hline Meaningfulness & & -0.48 & $<0.001$ & -0.40 & $<0.001$ \\
\hline Sense of coherence (total) & & -0.58 & $<0.001$ & -0.49 & $<0.001$ \\
\hline
\end{tabular}

$\rho$-Spearman's rank correlation coefficient, $p$-significance level. 
sistent with other studies presenting enhanced anxiety symptoms in CU patients [11, 13, 36-39]. Taking into consideration that almost one third of the CU group reported stress (which is usually experienced as fear [40]) as a causative factor, we could consider a specific vicious cycle formulation. Namely, experiencing a stressful situation can lead to disease development and exacerbation, and on the other hand, it could be an illness consequence $[6,11,13]$. There were no differences between study groups regarding the depression level. However, taking into account the scale interpretation, it appeared that 15 people reported depressive symptoms (10 individuals evaluated them as mild, 4 as severe and 1 as very severe). Studies of the other researchers [4, 11, 13, 37-39] confirmed a higher depression level in CU patients. Moreover, recent literature data indicate that adolescents who suffer from non-infectious urticaria are at a higher risk of developing major depression [41]. Weller et al. [42] demonstrated that different CU types could be associated with anxiety and depressive symptoms, which seemed to be less frequently encountered in patients with autoreactive chronic spontaneous urticaria.

Despite a simple lack of differences in the sense of coherence between CU patients and controls $(p>0.05)$, the interpretation of the obtained results seems to be of a key relevance. While referring the scores of the $\mathrm{CU}$ group to norms published in the literature $[17,43]$, they were in the range of high results (general score) and average ones concerning three SOC components. It can be a confirmation of an important role of SOC as a personal resource in coping with stress and discomfort related to disease [44] (bearing in mind a negative correlation between SOC and disease severity). The stronger SOC, the better possibilities to adjust to illness [26]. In other studies with dermatological patients suffering from psoriasis, rosacea and $\mathrm{CU}[13,25,45]$, the decrease in the sense of coherence was not noted either. On the contrary, a lower SOC was observed in other groups, such as in patients with epilepsy, chronic renal failure, asthma and depression, which are perceived as more life-threatening conditions than skin diseases, generally regarded as less dangerous [25, 46, 47]. The protective role of SOC was also confirmed regarding its negative relationships with depression and anxiety levels. Similar correlations were observed by other authors [13, 43, 48, 49]. Moreover, it was proved that the sense of coherence can be enhanced as a result of patients' education during climate therapy in psoriatics [50]. It could be worth investigating SOC improvement by the employment of the psychological intervention in urticaria patients.

As for study limitations, we employed DLQI to assess QoL in CU patients. Inevitably, a more specific tool such as the Chronic Urticaria Quality of Life Questionnaire (CU-Q2oL) [32] would generate more concrete data.

\section{Conclusions}

Taking into account the prevalence of mood disorders in the CU group, it would be useful to employ this aspect in screening in order to provide holistic professional care to patients. The SOC appeared to be a protective factor against anxiety and depression, so it is worth applying psychological interventions, enhancing personal resources, in a therapeutic plan for chronic urticaria individuals. It seems that holistic treatment provided by an interdisciplinary team of specialists from different fields, i.e. a dermatologist, allergologist, psychiatrist, psychologist, and psychotherapist could deliver the best cost-effective therapy to CU patients.

\section{Acknowledgments}

This study was supported by the statutory grant of the Medical University of Lodz no. 503/1-137-04/503-01 and grant for Young Researches of the Medical University of Lodz no. 502-03/1-137-04/502-14-030 and 502-03/1137-04/502-14-205.

\section{Conflict of interest}

The authors declare no conflict of interest.

\section{References}

1. Seneczko F, Kaszuba A. Allergic skin diseases [Polish]. In: Dermatology for cosmetologists. Adamski Z, Kaszuba A (eds). Elsevier Urban \& Partner, Wrocław 2010; 65-77.

2. Jabłońska S, Chorzelski T. Skin diseases for medical students and doctors [Polish]. Wydawnictwo Lekarskie PZWL, Warsaw 1994.

3. Alan S, Canan F, Karakas AA, et al. Temperament and character profiles of patients with chronic idiopathic urticaria. Postep Derm Alergol 2015; 32: 167-72.

4. Ozkan M, Oflaz SB, Kocaman N, et al. Psychiatric morbidity and quality of life in patients with chronic idiopathic urticaria. Ann Allergy Asthma Immunol 2007; 99: 29-33.

5. Conrad R, Geiser F, Haidl G, et al. Relationship between anger and pruritus perception in patients with chronic idiopathic urticaria and psoriasis. J Eur Acad Dermatol Venereol 2008; 22: 1062-9.

6. Zalewska-Janowska A. Psychodermatology in allergology [Polish]. Alerg Astma Immunol 2010; 15: 109-17.

7. O'Donnell BF, Lawlor F, Simpson J, et al. The impact of chronic urticaria on the quality of life. Br J Dermatol 1997; 136: 197-201.

8. Yosipovitch G, Greaves M. Chronic idiopathic urticaria: a "Cinderella" disease with a negative impact on quality of life and health care costs. Arch Dermatol 2008; 144: 102-3.

9. Mathias SD, Dreskin SC, Kaplan A, et al. Development of a daily diary for patients with chronic idiopathic urticaria. Ann Allergy Asthma Immunol 2010; 105: 142-8.

10. Uguz F, Engin B, Yilmaz E. Axis I and Axis II diagnoses in patients with chronic idiopathic urticaria. J Psychosom Res 2008; 64: 225-9.

11. Staubach P, Eckhardt-Henn A, Dechene M, et al. Quality of life in patients with chronic urticaria is differentially im- 
paired and determined by psychiatric comorbidity. Br J Dermatol 2006; 154: 294-8.

12. Engin B, Uguz F, Yilmaz, et al. The levels of depression, anxiety and quality of life in patients with chronic idiopathic urticaria. J Eur Acad Dermatovenereol 2008; 22: 36-40.

13. Brzoza Z, Kasperska-Zając A, Badura-Brzoza K, et al. Decline in dehydroepiandrosterone sulfate observed in chronic urticaria is associated with psychological sistress. Psychosom Med 2008; 70: 723-8.

14. Heszen I, Sęk H. Health psychology [Polish]. Wydawnictwo Naukowe PWN, Warsaw 2008.

15. Miniszewska J, Juczyński Z, Ograczyk A, et al. Health-related quality of life in psoriasis: important role of personal resources. Acta Derm Venereol 2013; 93: 551-6.

16. Miniszewska J, Chodkiewicz J, Ograczyk A, et al. Optimism as a predictor of health-related quality of life in psoriatics. Postep Derm Alergol 2013; 30: 91-5.

17. Koniarek J, Dudek B, Makowska Z. Sense of Coherence Questionnaire. Adaptation of The Sense of Coherence Questionnaire (SOC) A. Antonovsky'ego [Polish]. Przegl Psychol 1993; 36: 491-502

18. Heszen I. Clinical health psychology [Polish]. In: Clinical Psychology. Sęk H (eds). Wydawnictwo Naukowe PWN, Warsaw 2008; 222-43.

19. Bishop G. Stress and diseases [Polish]. In: Health Psychology. Bishop G (eds). Wydawnictwo Astrum, Wroclaw 2000; 177-211.

20. Młynek A, Zalewska-Janowska A, Martus P, et al. How to assess disease activity in patients with chronic urticaria? Allergy 2008; 63: 777-80.

21. Zuberbier T, Aberer W, Asero R. The EAACI/GA²LEN/EDF/ WAO guideline for the definition, classification, diagnosis and management of urticaria: the 2013 revision and update. Allergy 2014; 69: 868-87.

22. Szepietowski J, Reich A. Itch. Patomechanism, clinic, treatment [Polish]. Termedia, Poznan 2010.

23. Snaith RP, Zigmond AS. The hospital anxiety and depression scale. Br Med J 1986; 292: 344.

24. Zigmond AS, Snaith RP. The hospital anxiety and depression scale. Acta Psychiatr Scand 1983; 67: 361-70.

25. Kurowska K, Płachecka E. Sense of coherence and knowledge about the disease in psoriatics [Polish]. Now Lek 2010; 79: 445-50.

26. Eriksson M, Lindstrom B. Antonovsky's sense of coherence scale and the relation with health: a systemic review. J Epidemiol Community Health 2006; 60: 376-81.

27. Finlay AY, Khan GK. Dermatology Life Quality Index (DLQI) a simple practical measure for routine clinical use. Clin Exp Dermatol 1994; 19: 210-6.

28. Szepietowski J, Salomon J, Finlay AY, et al. Wskaźnik wpływu dolegliwości skórnych na jakość życia - Dermatology Life Quality Index (DLQI): Polish language version [Polish]. Dermatol Klin 2004; 6: 63-70.

29. Wysoczyńska K, Żebrowska A, Waszczykowska E. The assessment of quality of life in pemphigus patients. Przegl Dermatol 2013; 100: 139-45.

30. Ucmak D, Akkurt M, Ucmak F, et al. Investigation of dermatology life quality index and serum prolactin and serum dehydroepiandrosterone sulphate levels in patients with chronic urticaria. Asian Pac J Allergy Immunol 2014; 32: 293-9.

31. Liu BJ, Yao ZJ, Si AL, et al. Life quality of Chinese patients with chronic urticaria as assessed by dermatology life quality index. J Eur Acad Dermatol Venereol 2012; 26: 1252-7.

32. Brzoza Z, Badura-Brzoza K, Młynek A, et al. Adaptation and initial results of the Polish version of the GA2LEN Chronic
Urticaria Quality Of Life Questionnaire (CU-O, oL). J Dermatol Sci 2011; 62: 36-41.

33. Kocaturk E, Weller K, Martus P, et al. Turkish version of the Chronic Urticaria Quality of Life Questionnaire: cultural adaptation, assessment of reliability and validity. Acta Derm Venereol 2012; 92: 419-25

34. Jauregui I, de Frutos OFJ, Ferrer M, et al. Assessment of severity and quality of life in chronic urticaria. J Investig Allergol Clin Immmunol 2014; 24: 80-6.

35. Koti I, Weller K, Makris M, et al. Disease activity only moderately correlates with quality of life impairment in patients with chronic spontaneous urticaria. Dermatology 2013; 226: 371-9.

36. Balp M, Vietri J, Tian H, et al. The impact of chronic urticaria from the patient's perspective: a survey in five European countries. Patient 2015; 8: 551-8.

37. Barbosa F, Freitas J, Barbosa A. Chronic idiopathic urticaria and anxiety symptoms. J Health Psychol 2011; 16: 1038-47.

38. Hashiro M, Okumura M. Anxiety, depression, psychosomatic symptoms and autonomic nervous function in patients with chronic urticaria. J Dermatol Sci 1994; 8: 129-35.

39. Tsintsadze N, Beridze L, Tsintsadze N, et al. Psychosomatic aspects in patients with dermatologic diseases. Georgian Med News 2015; 243: 70-5.

40. Bries S. Overcome depression, stress and anxiety [Polish]. Samo Sedno, Warsaw 2011.

41. Chia-Lun K, Chi-Yen C, Hui-Ling H, et al. Increased risk of major depression subsequent to a first-attack and noninfection caused urticaria in adolescence: a nationwide population-based study. BMC Pediatr 2014; 14: 18.

42. Weller K, Koti I, Makris M, et al. Anxiety and depression seem less common in patients with autoreactive chronic spontaneous urticaria. Clin Exp Dermatol 2013; 38: 870-3.

43. Potoczek A, Niżankowska-Mogilnicka E, Bochenek G, et al. The relatioships between panic disorder and depression, and defense mechanisms, coherence and family functioning in patients with severe POChP [Polish]. Psychiatr Pol 2008; 5: 731-48.

44. Zirke N, Schmid G, Mazurek B, et al. Antonovsky's Sense of Coherence in psychosomatic patients - a contribution to construct validation. Psychosoc Med 2007; 4: Doc 03.

45. Zboralski K, Gernand A, Orzechowska A, et al. Sence of coherence and strategies of coping with stress among patients suffering from rosacea and depression - a comperative study [Polish]. Post Dermatol Alergol 2010; 27: 90-5.

46. Kurowska K, Bukowska M. Sense of coherence and suport among patients suffering from chronic renial failure treated with hemodialysis [Polish]. Urol Pol 2008; 61: 4-6.

47. Potoczek $A$. The differences in sense of coherence in severe, difficult asthma and asthma with hypersensitivity to aspirin and its relationships with intensity of panic disorder symptoms and depresssion in female and male subgroups [Polish]. Psychiatr Pol 2011; 45: 197-209.

48. Ogłodek E, Augustyńska B, Marek L, et al. Sense of coherence in persons suffering from psoriasis [Polish]. Pol Merkur Lekarski 2009; 27: 202-4.

49. Ponarovsky B, Amital D, Lazarov A, et al. Anxiety and depression in patients with allergic and non-allergic skin lesions. Dermatol Kosmetol 2011; 6: 62-7.

50. Langeland E, Robinson HS, Moum T, et al. Promoting sense of coherence: salutogenesis among people with psoriasis undergoing patient education in climate therapy. BMC Psychol 2013; 1: 11 